\title{
“ACERTANDO AS HORAS”: JOGO CARTOGRÁFICO COMO RECURSO DIDÁTICO GEOGRÁFICO NO ENSINO DE FUSOS HORÁRIOS
}

\author{
“Acertando as Horas": A cartographic game as a didactic and geographical resource to teaching time \\ zones
}

Tais Pires Oliveira

Mestranda em Geografia pelo PGE/UEM tais_piresoliveira@hotmail.com

Claudivan Sanches Lopes Professor do Departamento de Geografia da Universidade Estadual de Maringá claudivanlopes@gmail.com

Artigo recebido em 07/10/2016 e aceito para publicação em 19/11/2016

DOI: $10.12957 /$ tamoios.2016.25888

\begin{abstract}
Resumo
Este trabalho tem por objetivo discutir possibilidades do uso de jogos cartográficos como recurso didático impulsionador da melhoria do processo de ensino e aprendizagem do conteúdo fusos horários no ensino de Geografia. Apresenta-se, assim, como modo de contribuição ao desenvolvimento dessa temática a análise do processo de produção, implementação e avaliação de resultados do jogo "Acertando as Horas". Metodologicamente, partindo das características e intenções desse conteúdo no currículo escolar, buscaram-se subsídios teóricos relativos ao uso de jogos no processo de ensino e aprendizagem em Geografia, na didática dessa disciplina escolar, dentre outros temas importantes para a pesquisa. O jogo produzido, implementado em classe de Ensino Médio em um colégio da rede particular da cidade de Maringá, PR, foi avaliado por meio da aplicação de questionários antes e depois da experiência didática, cujo objetivo fundamental foi identificar, respectivamente, o conhecimento prévio e os avanços no conhecimento dos alunos resultante do jogo. Foi possível mostrar, sem negar o papel essencial do professor como mediador do processo educacional, a importância desse tipo de recurso na promoção de uma aprendizagem mais significativa para os alunos. Evidenciou-se, assim, a contribuição deste jogo como material didático que de fato contribui para o aperfeiçoamento do ensino do conteúdo de fusos horários, bem como no desenvolvimento de habilidades geográficas a ele associadas, tais como de orientação e de localização.
\end{abstract}

Palavras-chave: Jogo; Didática da Geografia; Habilidades geográficas; Fusos horários.

\begin{abstract}
The aim of this study is to discuss the possibilities of usage of cartographic games as a didactic resource that boosts the improvement of the learning and teaching processes on the subject of time zones in Geography. Thus, as a means of contribution to the development of the theme, it is presented the analysis of the processes of production, implementation and evaluation of the results of the game Acertando as Horas. As for methodology, starting from the characteristics and intentions of this topic in the course syllabus, relevant theoretical material on the usage of games in the process of teaching and learning geography was searched. The produced game was used with a High School classroom in a private school in Maringá, PR, and it was evaluated through questionnaires about before and after the didactic experience, whose main objective was to identify previous knowledge and advances in knowledge resulting of the game, respectively. It was possible to show, without denying the essential part of the teacher as a mediator in the educational process, the importance of this kind of resource to promote more significant learning to students. Therefore, it was proven the contribution of this game as a didactic material which, in fact, contributed to the enhancement of teaching the content of time zones, as well as in the development of geographical abilities associated to it, such as orientation and placement.
\end{abstract}

Key words: Game; Didactic in Geography; Geographical abilities; Time zones. 


\section{Introducão}

A busca por novas metodologias e linguagens para o ensino de Geografia é tema recorrente na pesquisa e na prática profissional dos professores dessa área do currículo escolar. Considerando as características da sociedade atual, visa contribuir para tornar o processo de ensino e aprendizagem mais dinâmico, atrativo e significativo, proporcionando aos alunos elementos que lhes permitam compreender a produção e transformação do espaço geográfico mediante a realização de diferentes leituras, comparações, relações e análises das informações. Entende-se que a qualidade dos procedimentos didático-pedagógicos utilizados pelos professores em sala de aula refletem diretamente na compreensão e apreensão dos conteúdos pelos alunos e que, nesse sentido, a procura pela inovação de modo geral e particularmente a inserção dos jogos educativos no ensino de Geografia possibilita a estes "[...] compreender os conteúdos, fixar conhecimentos, construir seu saber de modo prático, dinâmico e eficiente" (VERRI; ENDLICH, 2009, p. 70).

Assim, o objetivo deste trabalho é propor e avaliar, tendo em vista as dificuldades identificadas no ensino e aprendizagem do conteúdo de fusos horários na disciplina de Geografia na Educação Básica, a utilização de jogos cartográficos como recurso didático impulsionador da melhoria desse processo e desencadeador de habilidades geográficas. Considera-se, nesse contexto, iluminada pelos pressupostos da didática da Geografia, a importância de aprofundar o estudo dessa temática em sua interface com as possibilidades oferecidas pela cartografia escolar. Busca-se, assim, contribuir para uma aprendizagem significativa dos conteúdos para formar alunos conscientes, com habilidades geográficas, para empreenderem uma leitura crítica da sociedade.

Nesse sentido, fundamentam-se em aportes teóricos para discutir a utilização do jogo como um recurso didático lúdico por meio dos estudos de autores como Rau (2012) e Costa (2005), mais especificamente sua utilização no ensino de Geografia utilizando as reflexões de Breda (2013), Castellar e Vilhena (2011), Silva (2014) e Callai (2011). Dessa forma, no uso de diferentes recursos didáticos mais especificamente do jogo, é relevante destacar as práticas construídas pelos docentes ao longo de sua trajetória. Assim, dialoga-se com Libâneo (2001; 2008) Oliveira (2015) e Lopes (2015) a respeito da didática e do desenvolvimento dos saberes que conduzem a uma didática da Geografia.

O trabalho aqui apresentado compõe-se de cino momentos: no primeiro discute-se a utilização dos jogos como um material lúdico no ensino de Geografia; no segundo empreende-se uma breve reflexão sobre o conteúdo fuso horário no currículo escolar; no terceiro discute-se aspectos rlacionados à didática e à didática da Geografia; no quarto momento são apresentadas as orientações metodológicas adotadas para a realização do trabalho; e no quinto momento discorrem-se acerca das discuções referentes ao jogo "Acertando as Horas".

\section{Os jogos no processo de ensino e aprendizagem da Geografia}

São muitas as discussões que, no campo do ensino de Geografia, apontam a necessidade de se trabalhar os conteúdos em sala de aula a partir de circunstâncias "práticas", correspondendo aos anseios dos alunos, hoje mais inquietos e questionadores. Almeja-se estimular, nos estudantes, uma visão crítica e mais participativa por meio da criação de situações didáticas atraentes e marcadas por estratégias diversas.

Dentre essas práticas, considera-se que as atividades lúdicas de modo geral e, sobretudo, os jogos podem ser utilizados pelo professor como um estímulo para a construção 
do conhecimento pelos alunos em sala de aula. Rau (2012, p. 31) assinala que o lúdico ou a ludicidade "[...] se define pelas ações de brincar que são organizadas em três eixos: o jogo, o brinquedo e a brincadeira". Na visão de Costa (2005, n.p.), "A palavra lúdico vem do latim ludus e significa brincar. Neste brincar estão incluídos os jogos, brinquedos e divertimentos e é relativa também a conduta daquele que joga, que brinca e que se diverte."

Como recurso didático-pedagógico, a ludicidade, adverte Rau (2012), deve alcançar objetivos educacionais, ou seja, deve estimular o desenvolvimento humano e contribuir para a evolução de determinadas habilidades. Assim, como apontado anteriormente, as atividades lúdicas empregadas no processo educacional visam contribuir de forma divertida, seguindo sua função pelo ato de brincar ou jogar, porém intencionalmente planejadas com a finalidade de possibilitar aos alunos avançarem no conhecimento através de uma prática emancipadora.

No contexto brasileiro, observa-se que os estudiosos da ludicidade vêm, já há algumas décadas, "[...] apontando o jogo como um instrumento pedagógico muito significativo e de grande valor social, oferecendo, assim, diferentes possibilidades educacionais" (RAU, 2012, p.21). O jogo estimula os alunos para as interações sociais, desperta para a participação mais ativa nas ações cotidianas e permite que estes se expressem emocionalmente e realizem descobertas pessoais e educacionais.

Nessa perspectiva, os jogos podem ser utilizados no processo de ensino e aprendizagem como uma forma de contribuir para a construção do conhecimento pelos alunos e ajudá-los a desenvolver habilidades de natureza geográfica de forma prazerosa. Revelam-se, assim, como assinala Breda (2013), um fator dinamizador do processo de aquisição de conhecimento.

O jogo possibilita a interação entre os próprios alunos e entre estes e o professor, e estimulam o estabelecimento de relações de aprendizagem, afetivas e de socialização. Como defendem Castellar e Vilhena (2011, p.45), "Os jogos e as brincadeiras são entendidos como uma situação em que se tem de tomar decisões e cooperar com outros jogadores". O uso de jogos e situações-problemas, conforme Silva (2014, p. 143), contribui eficazmente para uma situação de ensino "[...] que confere ao aluno um papel ativo na construção dos novos conhecimentos, pois permite a interação com o objeto a ser conhecido incentivando a troca de coordenação de ideias e hipóteses diferentes, além de propiciar conflitos, desequilíbrios [...]".

Pode-se depreender, portanto, que o jogo possui duas funções: a primeira seria a função lúdica, um brincar livre e prazeroso, e a segunda seria sua função educacional, um brincar direcionado para um tema específico e com objetivos de aprendizagem. Essa integração das funções deve ser alcançada criativamente pelo docente ao organizar um ambiente rico e dinamizador das interações.

Moratori (2003, p.12) sustenta que "[...] o jogo, em seu aspecto pedagógico, se apresenta produtivo ao professor que busca nele um aspecto instrumentador, e, portanto, facilitador da aprendizagem muitas vezes de difícil assimilação." Dessa forma, cabe ao professor, como mediador social do conhecimento, a seleção dos conteúdos trabalhados por meio dos jogos e sua adequação às potencialidades cognitivas dos alunos. Diante da relevância que os jogos podem ter no ensino é necessário cultivar a consciência de que estes devem ser utilizados com precaução em sala de aula. Deve-se evitar, por exemplo, que a atividade possa se tornar um material que desperte uma competição negativa, ou que se constitua em mera atividade recreativa. A "competição" durante o jogo precisa ser sadia e natural, em que o aluno não busque tão somente superar seus desafios, mas agregar conhecimentos a fim de obter um bom desenvolvimento (BREDA, 2013).

No ensino de Geografia, os jogos devem proporcionar a apropriação de conceitos, habilidades/procedimentos e valores que caracterizam essa área do currículo escolar e revelem, ao mesmo tempo, a relevância da educação geográfica na atualidade; ou seja, devem 
revelar, claramente, sua geograficidade. Assim, entende-se, de acordo com Castellar e Vilhena (2011), que a função pedagógica do jogo consiste em sua potencialidade para superar práticas tradicionais ultrapassadas, mas ainda presentes no processo de ensino e aprendizagem dessa disciplina escolar. Essa afirmativa vem ao encontro das necessidades apresentadas na perspectiva de uma educação geográfica que visa, considerando suas especificidades, trabalhar os conteúdos selecionados pelo currículo em uma dimensão que busca torná-los mais atrativos para que os alunos, desde a perspectiva geográfica, visualizem seu papel na sociedade e possam pensar o espaço em que vivem de maneira local e global.

Callai (2011) confirma que, “[...] pode-se acreditar que a educação geográfica apresenta-se hoje como a possibilidade de tornar significativo o ensino de uma disciplina presente na educação básica, que traz em seu conteúdo a possibilidade do debate a respeito das questões do mundo da vida". Defende-se, assim, que a utilização de novas linguagens é importante para o pleno desenvolvimento do processo de ensino e aprendizagem de modo geral e, mais especificamente, levando em conta as preocupações particulares do ensino de Geografia.

O jogo, por conseguinte, como um recurso didático no ensino de Geografia, pode contribuir para que os alunos articulem a teoria e a prática, auxiliando-os no desenvolvimento do raciocínio geográfico e promovendo uma educação geográfica efetiva. Trata-se de um material que prende a atenção dos alunos, despertando um interesse "natural" que facilita o processo de ensino e aprendizagem e auxilia na construção de habilidades como de orientação, localização, representação cartográfica e de leitura de mapas conforme o jogo trabalhado pelo professor. Nessa direção, Castellar e Vilhena (2011, p.44) sustentam que:

A relevância de se trabalhar nesta perspectiva como didática da educação geográfica é grande, na medida em que auxilia o desenvolvimento intelectual do aluno que, aprendendo melhor, vivencia as atividades e é colocado em situações de desafio, organizando esquemas e raciocinando sobre o conteúdo em questão.

Entende-se que, a critério do professor e considerando os objetivos estabelecidos, os jogos podem ser utilizados de diferentes modos e em diferentes momentos do processo de ensino e aprendizagem, seja para a introdução de um novo conteúdo, finalização ou mesmo como instrumento de avaliação do nível de conhecimento dos alunos. O desafio sempre será articular as possibilidades do jogo àquelas habilidades geográficas que se quer, por meio dele, desenvolver nos alunos.

O jogo, dessa maneira, favorece o desenvolvimento nos alunos de habilidades, procedimentos e mesmo atitudes que caracterizam essa área do currículo escolar. Ao jogar o jogo, os alunos devem exercitar ou interiorizar modos de pensar, de raciocinar e de investigar próprios da ciência ensinada. Assim, faz todo sentido investir, como pontua Libâneo (2008), na compreensão das relações existentes entre a didática e a epistemologia das disciplinas escolares. Nessa vertente, a didática "[...] somente faz sentido se estiver conectada à lógica científica da disciplina que é ensinada" (LIBÂNEO, 2008, p. 67).

Nessa perspectiva elaborou-se o jogo denominado "Acertando as Horas", em que se busca desenvolver e aprimorar nos alunos noções cartográficas, especialmente do conteúdo de fuso horário, pois se entende que os jogos cartográficos podem ser utilizados para estimular a compreensão dos conteúdos selecionados pelo currículo escolar, instigar o desenvolvimento de raciocínios geográficos e, mais amplamente, enriquecer o desenvolvimento e crescimento intelectual dos alunos.

Intenciona-se que os discentes possam compreender o conceito de fuso horário, bem como seu funcionamento, não só na "teoria", mas também em suas implicações práticas. O jogo, como se pode observar, também propicia o trabalho interdisciplinar com a matemática, 
já que os jogadores são chamados a realizar operações e envolvem a escala e cálculos realizados a cada jogada, seja de adição, subtração ou multiplicação.

\section{Os fusos horários}

Os fusos horários constituem um conteúdo curricular clássico no ensino de Geografia que frequentemente aparece associado à aprendizagem das noções/habilidades de orientação e de localização. É, portanto, no contexto de apresentação ou aprofundamento da linguagem cartográfica, aspecto fundamental para a consecução da educação geográfica, que esse conteúdo aparece. Trata-se, sem dúvida, de uma referência importante para a compreensão de outros conteúdos geográficos, como, por exemplo, a leitura crítica de mapas que, até certo ponto, condiciona a compreensão da dinâmica de circulação de pessoas, mercadorias e capitais pelo espaço geográfico mundial.

Sabe-se que a definição das horas, há séculos atrás, era realizada pela observação do Sol e seu "movimento" diário no céu; os viajantes de terra e de mar acertavam as horas a cada parada. Com os avanços marítimos e as necessidades que surgiram em consequência do avanço da navegação, somados aos interesses políticos, ao longo do processo histórico foi necessário estabelecer os fusos horários para que os relógios de uma mesma localidade marcassem a mesma hora.

Muitos países utilizavam seus próprios meridianos para marcar a hora local. Após muitas divergências políticas, particularmente entre Estados Unidos, Grã-Bretanha e França, como aponta Seemann (2013) em seu trabalho "Linhas imaginárias na cartografia: a invenção do primeiro meridiano", estabeleceu-se o Meridiano de Greenwich como primeiro meridiano oficial. De acordo com Sobreira (2012, p. 12),

\footnotetext{
A escolha do Meridiano de Greenwich, passando pelo Observatório de Greenwich no Reino Unido, se deu a partir de 1 de outubro de 1884, na Conferência Internacional do Meridiano, em Washington - D.C., nos Estados Unidos da América, ocasião em que tal decisão foi apoiada por representantes de 26 países, contrariando as pretensões dos franceses em restabelecer o Meridiano Inicial no Observatório de Paris, o que demonstra ter sido esta uma deliberação meramente política.
}

Com o estabelecimento do meridiano oficial, fixou-se também a Linha Internacional de Mudança de Data (longitude $180^{\circ}$ ), que se fixou no Anti-Meridiano de Greenwich. Para a operacionalização dos fusos horários, tem-se que os $360^{\circ}$ da esfera terrestre são divididos pelas 24 horas (aproximadas) do movimento de rotação. Essa divisão resulta em $15^{\circ}$ de rotação corresponde a 1 hora do dia.

Nesse âmbito, como declara Sobreira (2012, p. 13), "Cada fuso horário é delimitado em um intervalo de $15^{\circ}$ de longitude, por dois outros meridianos, com isso, em $360^{\circ}$ de longitude completa ao longo do Equador terrestre há 24 "fusos geométricos" delimitados por meridianos limítrofes, entre si, e um meridiano central ao fuso". Isso estabelece a hora verdadeira de cada fuso horário.

Para manter um horário unificado em alguns territórios, evitando que pequenos países e até mesmo cidades possuíssem dois fusos, foram realizadas adaptações por acordos e conveniências políticas estabelecendo-se a hora legal ou limites práticos dos fusos horários.

A partir do movimento de rotação da terra, de Oeste para Leste, tomando-se um ponto de referência, nesse caso o Meridiano, as áreas no Leste são iluminadas pelo Sol primeiro que as áreas a Oeste, e assim, segundo Sobreira (2012, p. 12), “[...] os fusos horários a Leste de 
Greenwich estão adiantados com relação a Greenwich e os fusos horários ao Oeste de Greenwich estão atrasados".

Este conteúdo, como apontado anteriormente, mostra-se importante no ensino da disciplina de Geografia, está-se diante de um pré-requisito relevante para aprendizagens futuras e que normalmente revela-se de difícil compreensão para os alunos; trata-se de um conteúdo que solicita uma didática especial capaz de torná-lo significativo para os discentes.

\section{Didática e didática da geografia}

Campo da Pedagogia, a didática estuda as relações envolvidas no processo de ensino, bem como os conhecimentos que unem a teoria e a prática educacional. A esse respeito, Libâneo (2001, p.2) define a didática como

[...] uma disciplina que estuda o processo de ensino no seu conjunto, no qual os objetivos, conteúdos, métodos e formas organizativas da aula se relacionam entre si de modo a criar as condições e os modos de garantir aos alunos uma aprendizagem significativa.

A didática não se finda em um método pronto de ensinar, ela se apresenta na construção da prática pedagógica em que o educador desenvolve diversas ações, linguagens e exemplos na busca de concretizar uma aprendizagem efetiva. A didática, por conseguinte, "[...] trata dos objetivos, condições e meios de realização do processo de ensino, ligando meios pedagógico-didáticos a objetivos sociopolíticos" (LIBÂNEO, 2001, p.2).

$\mathrm{Na}$ Geografia escolar, se faz necessário superar o aspecto meramente "conteudista" e alcançar um trabalho pedagógico que permita aos alunos compreender o mundo e, sem descuidar dos conteúdos, neles desenvolver habilidades geográficas. Deve-se, então, pensar o papel do professor ao desenvolver métodos didáticos e criar um "ambiente" que permita e potencialize esse avanço no pensamento dos alunos.

Lopes e Pontuschka (2011, p. 97) pontuam que "[...] a tarefa de ensinar Geografia exige que o professor domine, simultânea e integradamente, seus temas e conteúdos, sua significância social, seu sentido pedagógico e as formas mais adequadas de, em um determinado contexto, representá-los aos alunos". Isso aponta para uma docência de qualidade, levando em consideração a constante elaboração da prática e do conhecimento docente, alcançando a Didática da Geografia. A construção e o desenvolvimento da didática da Geografia dependem, portanto, da articulação entre os conhecimentos da ciência geográfica - nesse caso específico, os fusos horários - e os conhecimentos pedagógicos em uma complexa atividade, atingindo, nas palavras dos autores, a habilidade de transformar os diversos conteúdos geográficos em conteúdos de ensino (LOPES e PONTUSCHKA, 2011; LOPES, 2015).

O professor de Geografia necessita, como assinalado anteriormente e à luz dos diversos contextos de sua prática, dominar as bases epistemológicas da ciência geográfica em sua inter-relação com os conhecimentos didático-pedagógicos. Atrelando-os de modo hábil, pode construir uma didática própria da disciplina e, desse modo, alcançar um ensino significativo que atinja os objetivos propostos. Pode-se, assim, em consonância com Oliveira (2015, p.45), definir a Didática da Geografia como:

[...] um conjunto de saberes que, considerando os conteúdos desta disciplina, busca as formas mais adequadas para, no contexto social do aluno, promover a educação geográfica. A Didática da Geografia escolar deve contribuir para a construção de conhecimentos geográficos que facilitem uma reflexão crítica acerca da sociedade 
na qual os alunos vivem e, principalmente, sobre o espaço que ocupam, compreendendo como este é (re) organizado no seu cotidiano.

Aprender Geografia é, nesse sentido, aprender a pensar e atuar por meio dos conceitos geográficos. É interiorizar, como assevera Oliveira (2015), o modo próprio de pensar e agir do geógrafo em seu esforço de interpretação geográfica da realidade. Dessa forma, Sacramento (2010, p.5) afirma que

O professor de Geografia, ao pensar determinado conteúdo, precisa estruturar suas aulas e prepará-las criando métodos de aprendizagem, fazendo o aluno perceber e transpor aquele conhecimento apreendido para seu cotidiano. Os instrumentos geográficos permitem ao aluno ler os códigos geográficos, seus fenômenos e suas linguagens, com o intuito de saber pensar geograficamente o espaço dialético em que vive (Grifos da autora).

Os alunos precisam aprender a manipular e analisar dados e informações e isso pode ser o ponto de partida da educação geográfica que se deseja realizar (CALLAI, 2011). A Geografia deve ser entendida por estes como parte de sua vida, presente em suas ações e nas ações que permeiam o espaço em que vivem. Dessa maneira, por meio da prática docente pautada em uma didática específica, ou seja, que considera em suas estratégias de ensino a lógica científica da ciência que lhe serve de referência, o professor de Geografia possibilita aos alunos construir conhecimentos e desenvolver habilidades que lhes favoreçam, desde a perspectiva geográfica, uma leitura crítica de mundo, ou seja, alcançar uma educação geográfica. Nessa direção, conforme Sacramento (2010, p.4),

Pensar Didática da Geografia é saber organizar os saberes geográficos e articulá-los com os saberes pedagógicos, buscando relacioná-los ainda com o saber do professor, o saber do aluno e o saber escolar. As ações realizadas promovem essas interrelações, para que a perspectiva de ensino e aprendizagem de Geografia seja concretizada.

Concretizar, considerando os diferentes conteúdos escolares afetos à Geografia escolar, as ações descritas pela autora é sem dúvida um grande desafio que aqui, nos limites deste texto, se busca contribuir para superar. Investe-se, desse modo, nas possibilidades didáticas do jogo "acertando as horas" em articular o epistemológico e o pedagógico envolvendo os alunos em uma atividade atraente, acessível e promotora de aprendizagem significativa. Trata-se de um esforço na direção de contribuir com o desenvolvimento da didática da Geografia e, mais amplamente, para o reconhecimento da importância social do trabalho docente.

\section{Metodologia}

O objetivo principal deste trabalho, como ressaltado, é apresentar a criação e utilização de um jogo cartográfico como recurso didático lúdico, impulsionador da melhoria do processo de ensino e aprendizagem do conteúdo de fusos horários desencadeador de habilidades geográficas. Metodologicamente, a pesquisa se iniciou com a realização de levantamento bibliográfico e análise de obras que discutem a utilização jogos, principalmente os jogos cartográficos como recurso didático para o ensino de Geografia com a finalidade de refletir sobre o uso dos jogos em sala de aula. No levantamento bibliográfico se aprofundou também nas discussões teóricas referentes à didática da Geografia. Outro ponto de embasamento da pesquisa foram as leituras e análises de obras que tratam do conteúdo de 
fusos horários e seu ensino, considerando sua importância para a compreensão da dinâmica do espaço geográfico na atualidade.

O processo de criação do jogo, como se detalha adiante, surgiu pela necessidade de um material que contribua para o processo de ensino e aprendizagem de fusos horários. Iniciou-se pela construção do tabuleiro e, posteriormente, das cartas que contêm as perguntas orientadoras do jogo; gradativamente, foram sendo realizadas correções e pequenas modificações das regras até que finalmente considerou-se que o jogo estava pronto para ser utilizado.

A implementação do jogo "Acertando as Horas" aconteceu em dois momentos distintos, mas combinados, em uma escola da rede particular de ensino do município de Maringá, Paraná1. A realização do trabalho ocorreu em uma turma de $1^{\circ}$ ano do Ensino Médio, composta por 50 alunos que tinham no momento da pesquisa entre 14 e 18 anos. $\mathrm{O}$ professor A, regente da turma, observou e acompanhou todo o trabalho.

No primeiro momento ou encontro, apresentou-se o jogo para os alunos como o intuito de clarificar os objetivos, a metodologia e a importância de sua participação para o sucesso da pesquisa. Ainda nesse primeiro momento e antes da implementação do jogo, foi aplicado aos alunos um questionário para a avaliação de seu conhecimento prévio sobre os fusos horários e sua funcionalidade.

No segundo momento, estavam presentes o professor regente da sala e 5 monitores, dentre eles a pesquisadora. Os alunos foram divididos em 5 grupos de 10 alunos, formando 5 grupos de 5 duplas e jogaram o jogo "Acertando as Horas". Ao término do jogo, foi aplicado um novo questionário de avaliação para verificar o conhecimento construído pelos alunos jogadores bem como para o recolhimento de possíveis propostas de melhorias por estes sugeridas quanto à sua funcionalidade.

Outros dois questionários focados no conteúdo de fusos horários e propriamente sobre o jogo foram respondidos pelo professor. Assim como no caso dos alunos, o primeiro questionário foi aplicado anteriormente à aplicação do jogo e o segundo posteriormente, visando identificar, considerando sua percepção, as dificuldades do ensino desse conteúdo e as possibilidades de aprendizagens relacionadas ao tema proporcionadas pelo jogo.

\section{O jogo "acertando as horas"}

A proposta central do jogo é que os alunos, conduzidos pelas informações contidas nas cartas, "viajem" por diversos países no tabuleiro e percebam a diferença de fusos horários e sua influência em sua vida cotidiana e nas diversas práticas humanas, como nas relações econômicas e na dinâmica comercial em âmbito global. Deseja-se que estes possam compreender o conceito de fuso horário, assim como seu funcionamento, não só na teoria, mas em suas implicações práticas para a organização da vida humana. Outros pontos abordados pelo jogo são o conceito de escala e interdisciplinarmente com a matemática cálculos de adição, subtração ou multiplicação realizados a cada jogada.

Com o desenvolvimento desse jogo em sala de aula, pretende-se que os alunos alcancem uma educação integrada que lhes possibilite se apropriar de uma visão mais ampla tanto local como global das dinâmicas espaciais e que possam contribuir efetivamente com seu processo de aprendizado e com a formação do raciocínio geográfico.

O jogo foi elaborado em programa computacional de desenho, utilizando-se como base para o tabuleiro o mapa de fusos horários (IBGE). O jogo, como pode ser observado na Figura 1, consiste em: 1 tabuleiro, 6 conjuntos de cartas, sendo cada um deles com nove cartas, as regras, 1 régua, e os peões (navios). 
Figura 1: Jogo "Acertando as Horas"

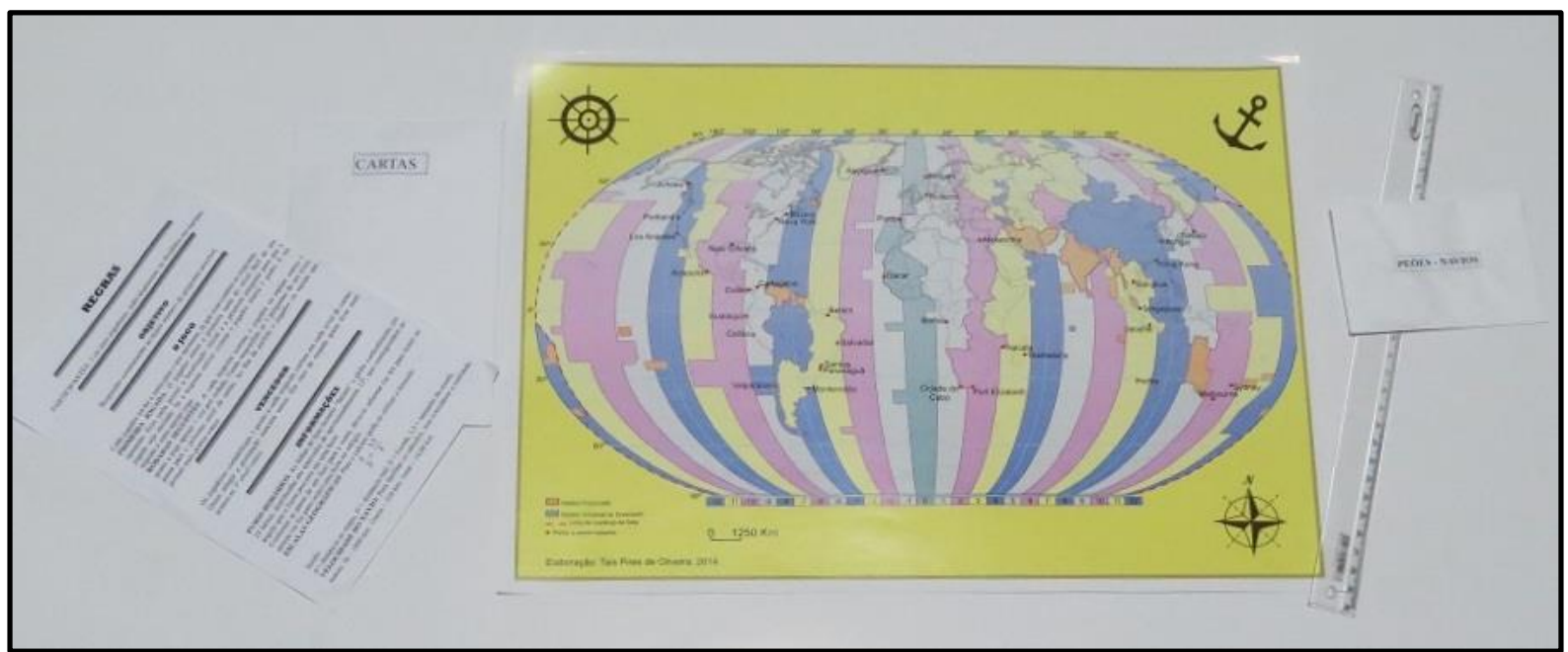

Fonte: A autora.

O tabuleiro, como se observa na Figura 2, é composto pelo mapa de fuso horário civil ou prático, no qual, além das informações contidas no mapa original, foram dispostas cidades portuárias, escolhidas e localizadas no tabuleiro de maneira que em todos os continentes, os quais houvessem portos, fossem comtemplados no jogo, buscando uma mobilidade e uma variação de diferença de fusos maior para as jogadas.

Figura 2: Tabuleiro do jogo

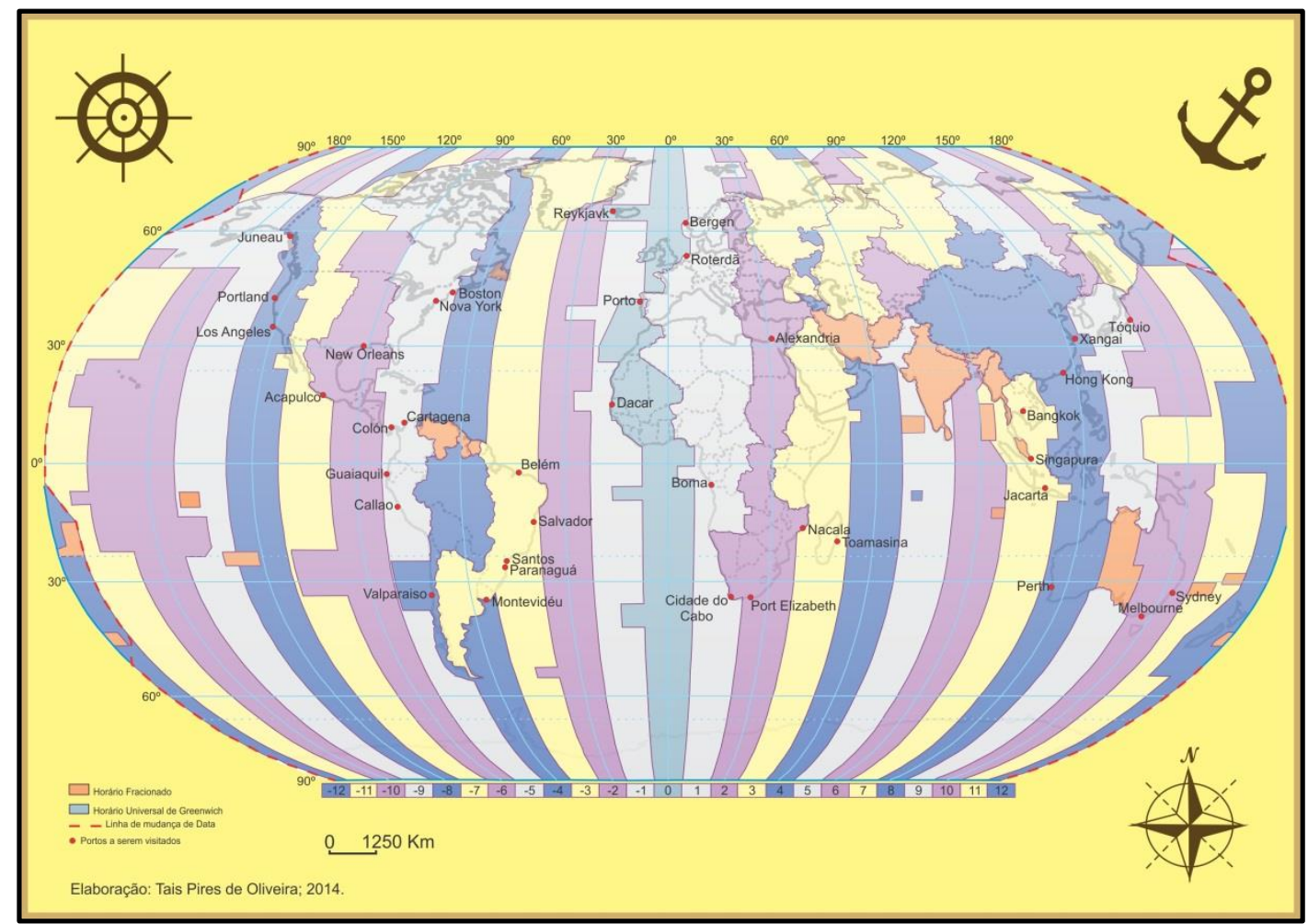

Fonte: A autora. 
Cada conjunto de cartas é constituído de 3 cartas de nível fácil representadas pela cor amarelo, 3 de nível médio representadas pela cor alaranjado e 3 de nível difícil representadas pela cor vermelho (Figura 3). Dessa forma, propôs-se um diferenciado nível do conhecimento, no qual os alunos avançam conforme suas possibilidades e consigam assimilar o conteúdo de maneira significativa.

As cartas de nível fácil, $1^{\text {o }}$ nível, consistem em perguntas relativas à diferença de horário entre duas cidades presentes no tabuleiro; para avançar de um porto para outro, o jogador precisa saber a calcular a diferença de fusos horários.

As cartas de nível médio, $2^{\circ}$ nível, questionam o horário em que o viajante chegará à outra cidade presente no tabuleiro, levando em consideração a diferença de fusos horários mais o tempo gasto na viagem. É importante destacar que o tempo gasto na viagem apontado no cartão é meramente ilustrativo e não condiz com a realidade, sendo utilizado para possibilitar aos alunos perceber a influência da diferença de horários de um ponto a outro.

Figura 3: Parte frontal das cartas do jogo

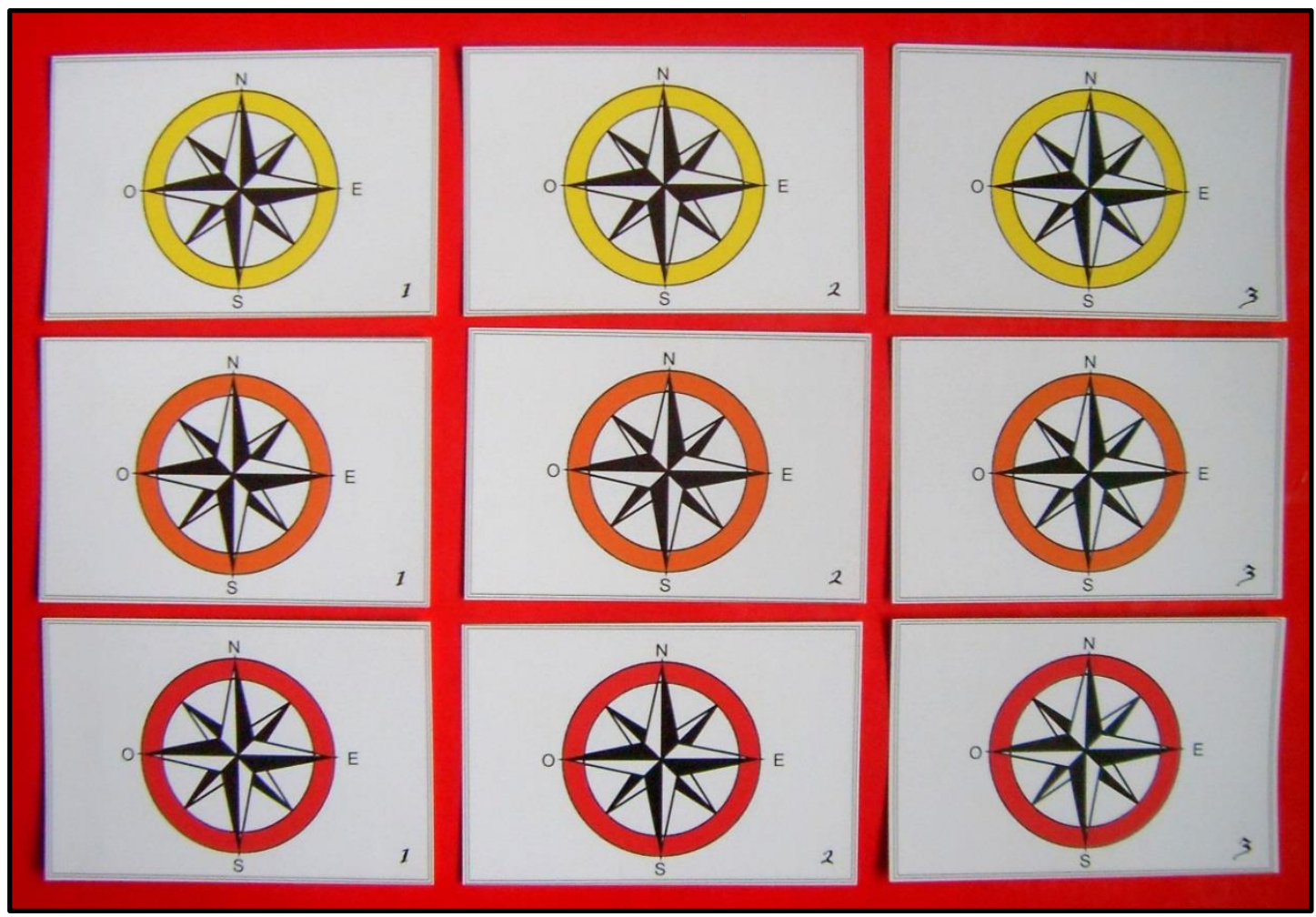

Fonte: A autora.

No $3^{\circ}$ nível, constituído por cartas com perguntas consideradas mais difíceis, os alunos necessitam de noções de escala para determinar o tempo de viagem e chegar à resposta. A utilização de todos os níveis de perguntas fica a critério do educador, que conhece a realidade e a necessidade de seus alunos.

\section{$\underline{O}$ jogo na sala de aula: resultados e discussão}

No primeiro encontro, como já indicado, foi efetuada uma conversa inicial sobre o trabalho e a aplicação do questionário de avaliação prévia a respeito dos conhecimentos dos 
alunos sobre a temática do jogo. Os alunos, como se observa no Gráfico 1, foram questionados em relação a sua atual compreensão sobre o funcionamento dos fusos horários e, como ilustra o Gráfico 2, 23 alunos, 47\%, classificaram sua compreensão como regular; destes, $6 \%$ afirmaram possuir uma ótima compreensão e $4 \%$ uma péssima compreensão.

Gráfico 1: Como você avalia sua atual compreensão sobre o funcionamento dos fusos horários?

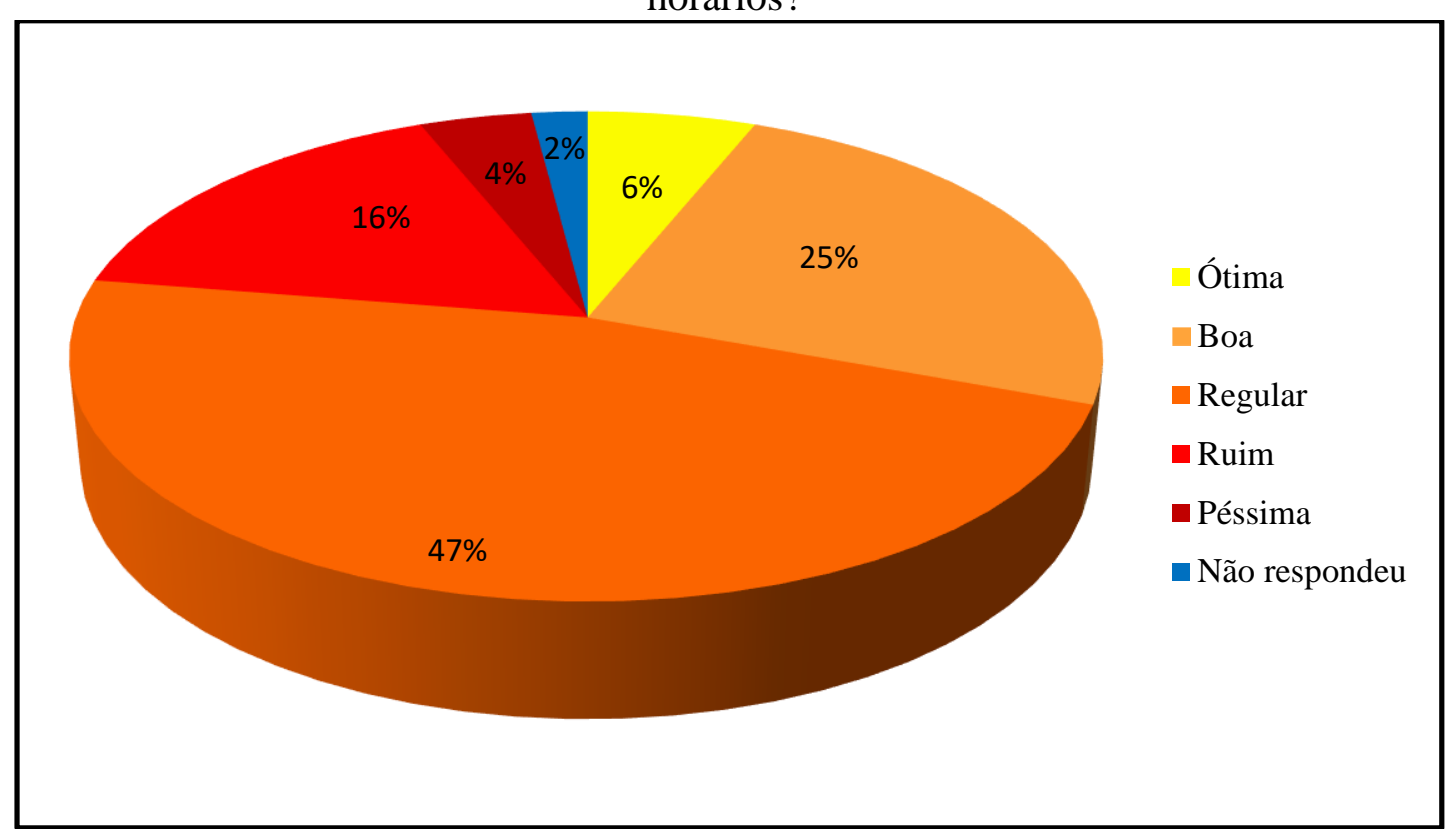

Fonte: A autora.

Detecta-se que os alunos têm dificuldade na operacionalização do conceito, e apontam a matemática como uma das maiores dificuldades, como revela esse depoimento: "Eu sinto um pouco de dificuldade pois envolve cálculos com as longitudes, isso dificulta demais para mim pois sou ruim na matemática" (Lucas, 17anos).

Nesse contexto, Pereira (2012) sublinha que os professores de Geografia, de modo geral, apresentam certas dificuldades no que se refere ao domínio dos processos de ensino relacionados aos conteúdos cartográficos e também com a matemática, o que dificulta ainda mais trabalhar o conteúdo de fusos horários, já que esses conhecimentos estão associados.

Entende-se que tais dificuldades se refletem diretamente na aprendizagem dos alunos, pois estes apontam os conhecimentos e habilidades veiculados por essa matéria - a matemática - como sendo os pontos de maiores dificuldades, como, por exemplo, ao realizarem as contas de diferença de fusos. Entretanto, um olhar mais atento aos dados coletados revela que as dificuldades residem também na imprecisão da interpretação centrada no insuficiente desenvolvimento de habilidades geográficas que permitam aos alunos a correta aplicação do conceito de fusos horários. Nas respostas dadas pelos alunos que possuem grandes dificuldades com a orientação e a localização observou-se esse fato, como aponta Leonardo (14 anos): "Fico perdido para qual lado aumenta e qual diminui as horas". Percebese, desse modo, que há uma dificuldade em compreender o próprio conceito de fusos horários mesclado com a falta de noções de orientação.

Outro exemplo é o depoimento da aluna Larissa (14 anos), que mesmo avaliando como boa sua compreensão sobre os fusos, afirmou: "Tenho dificuldade na hora de identificar a latitude e longitude e qual é norte, sul, leste ou oeste nas coordenadas geográficas". Assim, como informou o Professor A, os alunos demonstram não possuir algumas habilidades e 
conhecimentos geográficos e, com isso, têm dificuldades em aplicar adequadamente o conceito de fusos horários.

Retoma-se, mais uma vez, a possibilidade do uso de recursos didáticos que, mediados pelos saberes acumulados pelo docente, contribuam para a efetiva construção de conhecimentos e leve os alunos a desenvolverem, a partir da natureza dos conteúdos, habilidades a ele associadas e alcancem, gradativamente, uma educação geográfica.

Ao considerar as respostas obtidas com a pergunta: "Qual a importância dos fusos horários para a compreensão da atual dinâmica da sociedade global?”, os discentes revelam uma interpretação voltada para as relações comerciais, como pode ser observado na resposta de Paula (15 anos), que declarou: "Os fusos horários são importantes para organizar as cotações das bolsas de valores e planejar o tempo de saída e entrada de mercadoria entre países para não haver atrasos na economia". Na concepção do aluno Juliano (14 anos), a existência dos fusos horários "Interfere na abertura e fechamento das bolsas de valores mundiais, afetando a economia mundial". Nota-se que os alunos possuem a compreensão de como os fusos horários estão presentes no cotidiano, mesmo que de uma forma mais global e distante da realidade próxima de cada um.

Com o objetivo de avaliar o conhecimento prático dos alunos sobre a temática do jogo, ou seja, se além da compreensão do conceito e suas implicações para a organização do espaço geográfico mundial, podiam perceber sua aplicabilidade e função mais utilitária, formulou-se a seguinte questão: "A Copa do Mundo FIFA de 2018, $21^{\text {a }}$ edição do campeonato, terá como país sede a Rússia. Imaginando uma situação em que o Brasil jogará contra a Argentina em Moscou, às $19 \mathrm{~h}$ no horário local, e sabendo que o fuso horário da capital russa está três horas à leste do Meridiano de Greenwich e seis horas à leste do horário de Brasília, qual o horário em que o jogo será transmitido na cidade de Maringá?".

A resposta correta seria que o jogo será transmitido às 13h, pelo horário de Brasília. $\mathrm{O}$ Gráfico 2 ilustra que 52\% dos alunos responderam corretamente, 36\% das respostas foram incorretas e $12 \%$ dos participantes não responderam. É possivel, nesse último caso, que as respostas não foram dadas devido aos alunos não saberem executar os cálculos requeridos.

Gráfico 2: Horário de transmissão do jogo de acordo com a questão prática

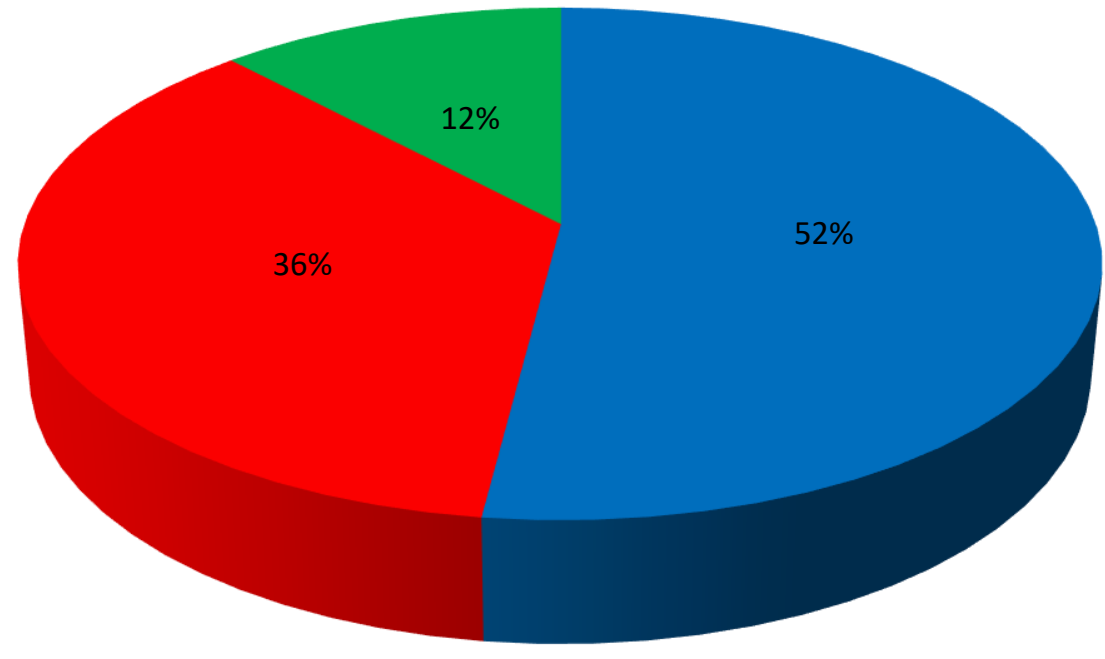

- Correto

Incorreto

- Não respondeu

Fonte: A autora. 
Um apontamento importante nessa questão é que os erros dos alunos não estão associados apenas às operações matemáticas, mas sim às habilidades geográficas como de orientação e de localização, pois em alguns casos observou-se que, ao invés de subtrair, devido ao Brasil estar a oeste da Rússia, estes utilizaram a soma na operação. Em alguns casos, verificou-se que o erro deveu-se à interpretação do comando da pergunta.

No segundo encontro, correspondente à segunda fase da pesquisa, a aula iniciou-se com a apresentação do jogo e em seguida procedeu-se à sua implementação. Primeiramente, os alunos demonstraram-se inquietos e alguns desinteressados pela proposta, demoraram um pouco para se organizar, talvez por ser uma turma grande, e tiveram dificuldades de entendimento do funcionamento do jogo. Observou-se uma distinção entre os grupos: um dos grupos de alunos estava totalmente desinteressado, respondendo muitas vezes no "chute", e por mais que houvesse intervenção e tentativa de incentivá-los não demonstraram muito interesse.

Um segundo grupo estava um pouco disperso, conversando sobre outros assuntos, porém avançaram no jogo e quando um dos monitores fazia alguma intervenção, estes participavam e focavam atenção no jogo. Entretanto, os outros 3 grupos demonstraram bastante interesse na atividade e avançaram bem no jogo, fizeram questionamentos e um deles, mesmo sem alcançar o último nível, perguntou sobre a resolução das perguntas mais difíceis para aprender.

Um ponto que chamou a atenção foi a leitura das cartas, pois muitas vezes onde estava escrito, por exemplo, $16 \mathrm{~h}$ os alunos pronunciavam 4 horas, o que fazia com que os colegas errassem as respostas.

Foi possível verificar que os alunos participantes da pesquisa detinham bom nível de conhecimento relacionado ao conceito ao se lembrarem, por exemplo, de que para oeste as horas "diminuem" e para leste "aumentam". Nesse sentido, o jogo reforçou a compreensão dos alunos no trabalho com o tema de maneira prática e lúdica.

Ao responderem o questionário avaliativo sobre o "Acertando as Horas", após terem jogado jogo, $90 \%$ dos alunos afirmaram que este contribui para a compreensão do funcionamento dos fusos horários, como pode ser observado no Gráfico 3. 
Gráfico 3: O jogo contribuiu para a compreensão do funcionamento dos fusos horários no planeta?

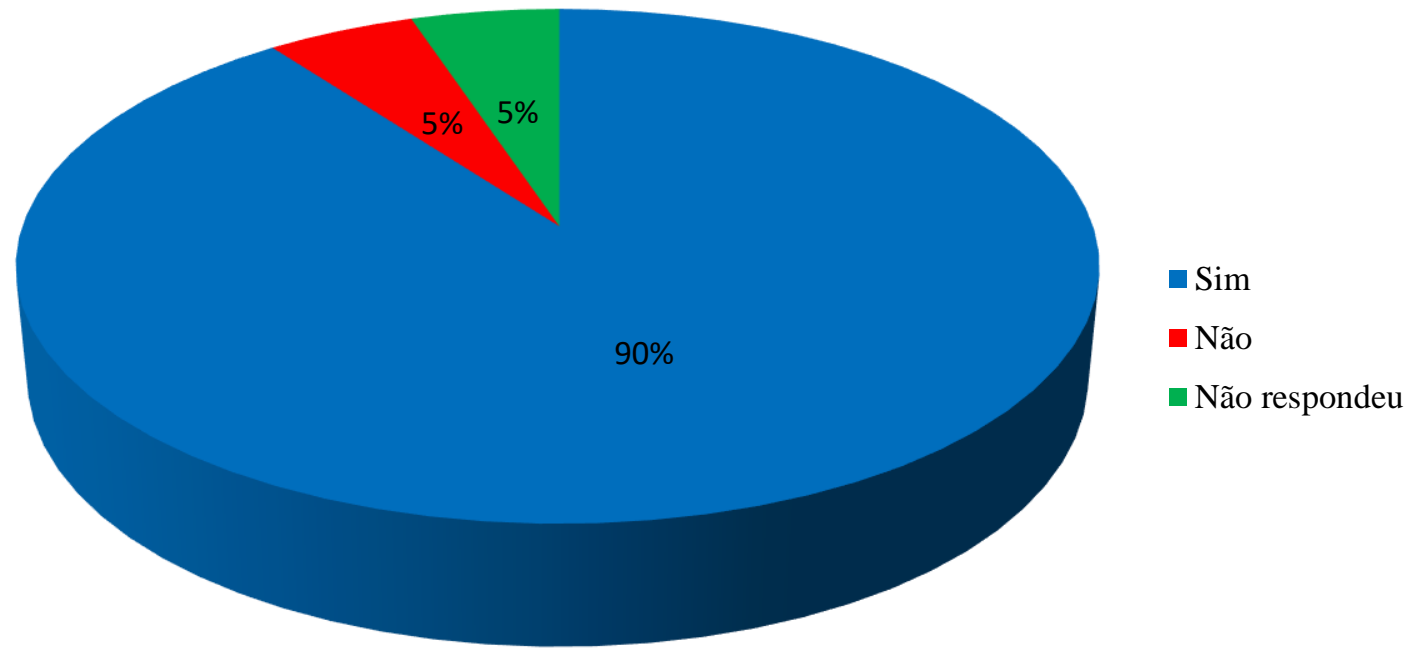

Fonte: A autora.

Todos os grupos responderam na totalidade às perguntas relativas às cartas do primeiro nível e parcialmente às do segundo nível, porém nenhum deles chegou ao terceiro nível, devido ao tempo da aula que se encerrou. Houve apenas questionamentos relativos a como resolver as questões do nível mais difícil, que seria o último. Isso reforça a necessidade de aulas geminadas ou conjugadas para o desenvolvimento total do jogo ou então a possibilidade de o professor escolher os níveis que prefere utilizar, de acordo com os objetivos das aulas e os conhecimentos da turma.

Esses níveis do jogo são propostos visando ao avanço no conhecimento dos alunos, através do desenvolvimento e aprimoramento do raciocínio geográfico. Cabe ao educador de Geografia atrelar o material as suas práticas e propostas pedagógicas, na construção de sua didática, mediando um ensino significativo.

Ao serem questionados sobre como avaliam as dificuldades do jogo, 31 alunos, ou seja, $75 \%$, como representado no Gráfico 4, responderam que avaliam as dificuldades como regulares. É importante frisar que, como assinalado anteriormente, nenhum dos grupos atingiu o último nível do jogo. 
Gráfico 4: Como você avalia as dificuldades do jogo?

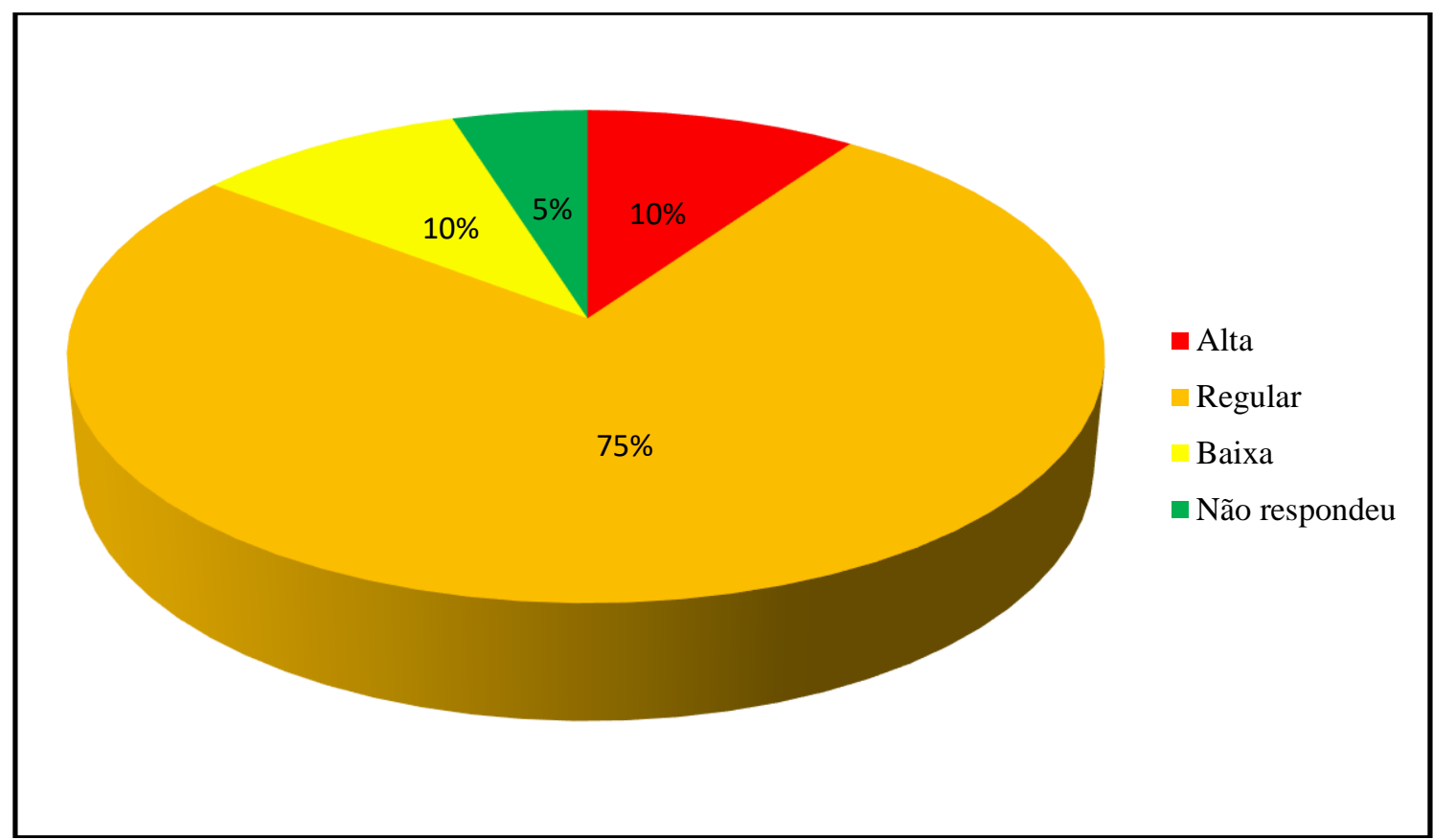

Fonte: A autora.

Ao considerar a questão que visava avaliar o conhecimento prático dos alunos após a implementação do jogo: "Em 2012 Londres cediou os Jogos Olímpicos de Verão, no dia 27 de julho às $20 \mathrm{~h}$ iniciou-se a abertura do evento, horário local. Sabendo-se que Maringá está a três horas para oeste do Meridiano de Greenwich, fuso horário de Londres, a que horas, no horário de Brasília, a abertura das Olimpiadas foi transmitida?", verificou-se, como ilustra o Gráfico 5, os seguintes resultados:

Gráfico 5: Horário de transmissão do jogo de acordo com a questão prática

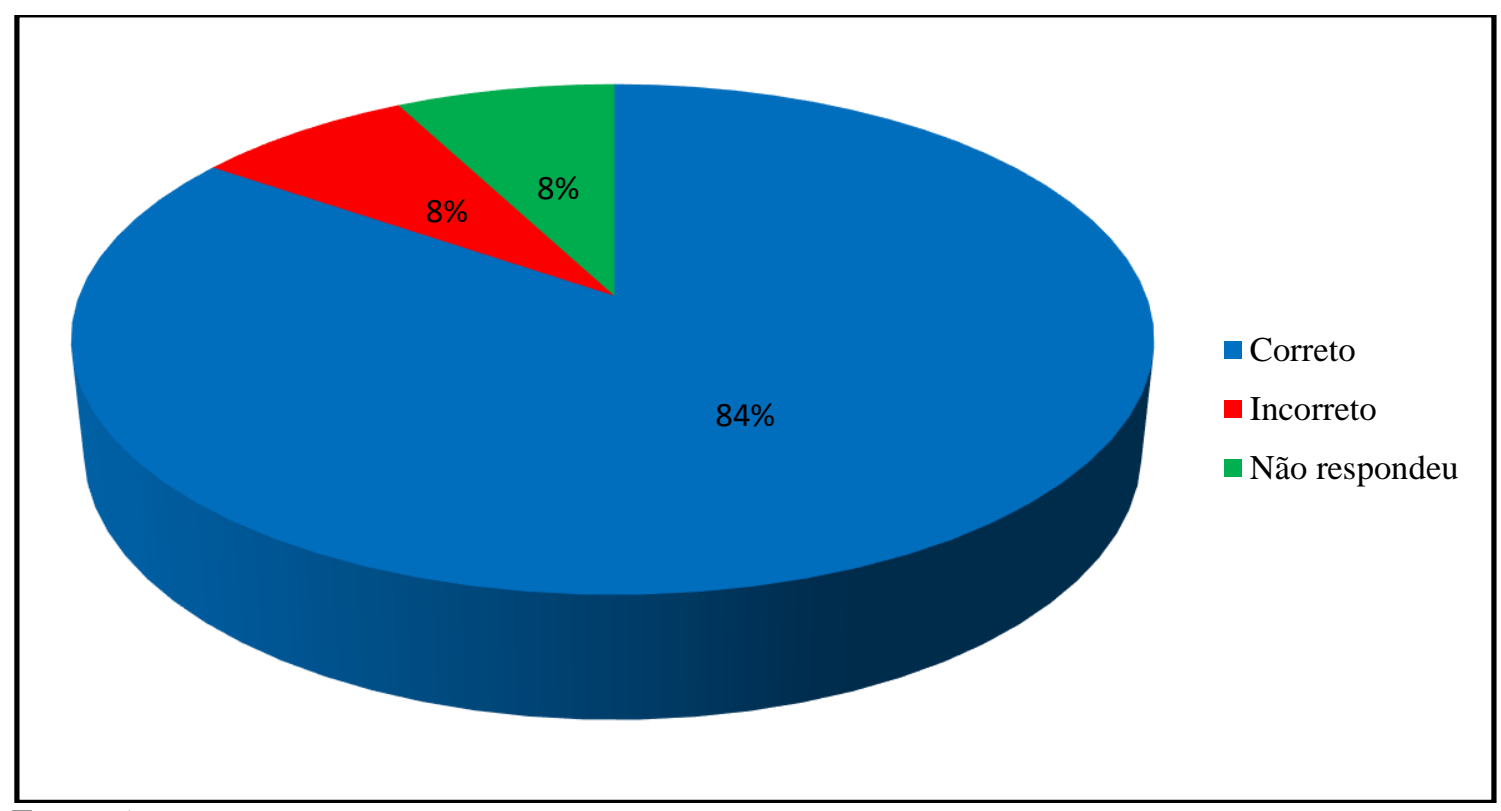

Fonte: A autora 
A resposta correta seria que a abertura foi transmitida em Maringá às $17 \mathrm{~h}$ e como demonstra o Gráfico 6, 84\% dos participantes responderam corretamente essa questão. Ao comparar-se com o questionamento da avaliação prévia, na qual $52 \%$ dos alunos acertaram a resposta, pode-se afirmar que o jogo contribuiu significativamente para que os alunos tivessem um avanço no conhecimento, demonstrando também que as habilidades geográficas que o jogo se propõe a construi foram desenvolvidas.

O Professor A, tendo em vista sua experiência e prática profissional, também realizou avaliação referente ao conteúdo de fusos horários e sobre o jogo. As considerações do educador são deveras relevante, pois é o quem possibilita a interação dos alunos com o conhecimento, utilizando recursos didáticos que tornem o processo de ensino e aprendizagem significativo.

O Professor A relatou que as dificuldades encontradas no ensino do conteúdo de fusos horários são a "localização espacial", a "orientação geográfica" (pontos cardeais), as "coordenadas geográficas", a "falta de pré-requisitos geográficos" e as dificuldades "dos alunos para realizarem cálculos".

Pode-se compreender que na visão do docente, além das dificuldades próprias do domínio da matemática, faltam habilidades geográficas para os alunos compreender o conteúdo e avançar de maneira mais profunda no conhecimento do tema. E para ministrar as aulas que tem como temática os fusos horários, o docente, segundo suas palavras, faz uso de recursos como "aulas com mapas, slides e inúmeros exercícios de fixação".

Ao ser questionado sobre as principais aprendizagens proporcionadas aos alunos pelo jogo, o Professor A afirmou ser a possibilidade do desenvolvimento das noções de "localização espacial, orientação geográfica e o desenvolvimento do cálculo". Demonstrou, portanto, que as habilidades, que antes faltavam aos alunos conforme apontamentos iniciais do docente como dificuldade no ensino do conteúdo fusos horários podem ser desenvolvidas mediante o jogo.

Nesse contexto, entende-se que o jogo vai ao encontro das necessidades encontradas pelo docente e pelos alunos no processo de ensino e aprendizagem do conteúdo de fusos horários, bem como auxilia em outros conteúdos geográficos presentes no currículo escolar que utilizam as habilidades ele associadas. Desse modo, os resultados da pesquisa são confirmados pelas ideias de Nascimento et al. (2013, p. 2) quando afirmam que "O jogo é um dos meios didáticos imprescindíveis para o professor em sala de aula. É um recurso que aglomera capacidades e competências variadas tanto para o desenvolvimento do professor na sua didática, como também no progresso da aprendizagem do aluno".

Ao ser questionado se o material é apropriado para o trabalho em sala de aula e se o usaria, a resposta do Professor A foi: "Sim! O conhecimento teórico poderia ser praticado no jogo". E ao avaliar o jogo, este relatou que este cumpre seu objetivo e sugeriu que na aplicação as equipes poderiam ser menores para uma melhor aprendizagem.

As afirmações do docente participante da pesquisa mostram que a utilização de jogos e mais especificamente do "Acertando as Horas" contribui para a formação do conhecimento geográfico em sala de aula tornando-o mais significativo, devendo ser utilizado de acordo com objetivos bem delineados e a partir das regras estabelecidas pelo professor.

\section{Consideracões finais}

Nesta pesquisa, investigou-se o uso do jogo como um recurso didático no ensino de Geografia de modo geral e, mais especificamente, o jogo "Acertando as Horas" como recurso didático lúdico impulsionador da melhoria do processo de ensino e aprendizagem e 
desencadeador de habilidades geográficas nos alunos. Defende-se, desse modo, que ao trabalhar o conteúdo fusos horários em sala de aula, o professor precisa, para além do livrotexto, utilizar materiais que estimulem os alunos a avançar no domínio desse conhecimento e construir os conceitos de forma conjunta, pois nem sempre o livro didático traz de forma satisfatória discussão completa sobre o assunto.

A proposta do jogo vem, portanto, no sentido de amenizar as dificuldades apontadas de modo geral pelos professores no ensino desse conteúdo e mais amplamente ao proporcionar aos alunos o desenvolvimento de raciocínios centrados no espaço, contribuindo para a efetivação de uma educação geográfica mais eficaz. A geograficidade do jogo, ou seja, seu sentido geográfico exprime-se na possibilidade que oferece para que os alunos, ao "viajarem pelo mundo", compreendam ou se aproximem da compreensão de que a existência dos fusos horários condiciona e até determina inúmeras práticas humanas e que isso, em consequência, é um aspecto importante para a compreensão da dinâmica do atual espaço geográfico na escala nacional e, fundamentalmente, na escala mundial. Trata-se, assim, de um recurso que possibilita aos alunos avançar na construção do conhecimento geográfico e alcançar gradativamente certa consciência geográfica.

Isso evidencia também a importância de o professor investir sua prática pedagógica buscando constantemente situações didáticas que melhorem seus resultados, sempre embasados teoricamente nos aportes da ciência geográfica. O jogo apresenta-se, assim, como um recurso didático lúdico que evidentemente não sana todas as dificuldades envolvidas no ensino desse conteúdo, mas que mediado criativamente pelo educador pode, efetivamente, de forma divertida e objetiva, proporcionar aos alunos a construção de conhecimentos que lhes sejam significativos.

Ressalta-se que o jogo em análise, como qualquer outro, pode tornar-se um material que desperta uma competição negativa ou que se constitua em mera atividade recreativa. Sugere-se, dessa maneira e contrariamente a essa possibilidade, que o jogo seja utilizado intencionalmente para promover a cooperação e a solidariedade entre os alunos e, pedagogicamente, visando ampliar e avançar no conhecimento.

Nesse sentido, em consonância com os aportes teóricos discutidos neste trabalho e a própria reflexão gerada pela aplicação do jogo, fica evidenciada a contribuição do jogo "Acertando as Horas" como material didático a ser usado pelo professor de Geografia; pode, de fato, contribuir para o ensino do conteúdo de fusos horários, bem como no desenvolvimento de habilidades geográficas a ele associadas tais como de orientação e de localização.

Verificou-se, ainda, a relevância de o docente optar pelas fases do jogo que melhor atendam aos objetivos da aula planejada, trabalhando, dessa forma, o conteúdo sempre ajustado ao tempo disponível para aplicação do jogo. Na implementação do jogo, identificouse que, para ser jogado em todas as suas fases, necessita de um tempo maior do que o tempo previsto em uma hora aula. Aponta-se, também, certa dificuldade da utilização do material em turmas com elevado número de alunos.

Conclui-se, assim, em conformidade com os autores que subsidiaram este trabalho, que os jogos podem contribuir para a elevação da qualidade do ensino de Geografia e que, mais propriamente, o jogo desenvolvido nesta pesquisa possibilita aos alunos desenvolver seu raciocínio geográfico. Para o docente, configura-se como uma ferramenta que cria diversas possibilidades para o ensino e a construção de suas práticas pedagógicas.

Espera-se que este trabalho seja um estímulo para novas pesquisas, tanto com o material aqui apresentado, que pode revelar ainda outras contribuições, como com a criação de novos materiais. E que estimule os docentes de Geografia a construir, de maneira criativa, suas práticas docentes edificando e estimulando o raciocínio geográfico nos alunos. 


\section{Nota}

1 - Para garantir o anonimato dos envolvidos na pesquisa, o nome do colégio não é exposto no trabalho. Do mesmo modo, utilizam-se nomes fictícios para o professor e os alunos participante.

\section{$\underline{\text { Referências }}$}

BREDA, T. V. O uso de jogos no processo de ensino aprendizagem na geografia escolar. 2013. 164f. Dissertação (Mestrado em Ensino e História das Ciências da Terra) Instituto de Geociências, Universidade Estadual de Campinas, Campinas.

CALLAI, H. C. Educação Geográfica: reflexão e prática. Ijuí: Unijuí, 2011. 320 p.

CASTELLAR, S. M. V. Currículo, educação geográfica e formação docente: desafios e perspectivas. Revista Tamoios. Ano II, No 2 - julho/dezembro 2006. p. 1-14.

CASTELlAR, S. VILHENA, J. Ensino de Geografia. São Paulo: Cengage Learning, 2011. (Coleção ideias em ação). 161 p.

COSTA, S. A formação lúdica do professor e suas implicações éticas e estéticas. Psicopedagogia on line. Educação e Saúde mental. 2005. [n.p.: s.n.] disponível em <http://www.psicopedagogia.com.br/new1_artigo.asp?entrID=692> Acesso em 11 set. 2015.

LIBÂNEO, J. C. Didática e epistemologia: para além do embate entre a didática e as didáticas específicas. In: VEIGA, I. P.; D’Avila, C. (Orgs.) Profissão Docente: novos sentidos, novas perspectivas. Campinas, SP, Papirus, 2008. p. 59-88.

LIBÂNEO, J. C. O essencial da didática e o trabalho de professor - em busca de novos caminhos. Goiânia, 2001. Disponível em $<$ http://novo.limaribeiro.net/File/Content/Document/pt-br/didatica-do-ensino-superior-oessencial-da-didatica.pdf> Acesso em 20 de set. de 2015.

LOPES, C.S. Didática da Geografia: Reflexões sobre um campo de pesquisa. In. XV Encuentro de Geógrafos de América Latina: Por una América Latina unida e sutentable - EGAL. Anais eletrônicos... Havana. 2015. v. 1. p. 1-15.

LOPES, C. S.; PONTUSCHKA, N. N. Mobilização e construção de saberes na prática pedagógica do professor de Geografia. Geosaberes, Fortaleza, v. 2 n. 3, p.88-104, 2011. Disponível em <http://www.geosaberes.ufc.br/seer/index.php/geosaberes/article/viewFile/89/ pdf38> Acesso em 30 de mar. de 2014.

MORATORI, P.B. Por que utilizar jogos educativos no processo de ensino aprendizagem?. UFRJ. Rio de Janeiro, p. 1-28, 2003. Disponível em <http://www.nce.ufrj.br/ginape/publicacoes/trabalhos/t_2003/t_2003_patrick_barbosa_morato ri.pdf> Acessado em 25 de Abril de 2014.

NASCIMENTO, I. T.; LIMA, F. M. A.; TEMÓTEO. A.S.S.G. O ensino e a aprendizagem através dos jogos concretos educativos. In: V FIPED Fórum Internacional de Pedagogia Fiped V - Volume 1, Número 2, ISSN 2316-1086. Campina Grande/PB: Realize Eventos e Editora, 2013. Disponível em < https://pibidpedcap.files.wordpress.com/2013/01/o-ensino-ea-aprendizagem-atravc3a9s-dos-jogos-concretos-educativos1.pdf> Acesso em 25 de set. 2015. 
OLIVEIRA, J. R. O conhecimento pedagógico do conteúdo e a didática da geografia. 2015. 144f. Dissertação (Mestrado em Geografia) Programa de Pós-Graduação em Geografia da Universidade Estadual de Maringá. Maringá.

PEREIRA, P. R. DE C. Os problemas no ensino-aprendizagem dos conteúdos de Cartografia com bases matemáticas: uma avaliação no âmbito da disciplina de geografia do $6^{\circ}$ ano na rede pública de ensino de Anápolis, Goiás. 2012. 112 f. Dissertação (Mestrado) - Universidade Federal de Goiás, Instituto de Estudos Sócio-Ambientais.

RAU, M. C. T. D. A ludicidade na educação: uma atitude pedagógica. Curitiba: Inter Saberes, 2012.

SACRAMENTO, A. C. R. Didática e Educação Geográfica: algumas notas. UniPluri/Versidad. Facultad de Educación- Universidad de Antioquia. Medellín, Col. Vol.10, No.3, p. 1-9, $2010 \quad-\quad$ Versión Digital. Disponível em < http://aprendeenlinea.udea.edu.co/revistas/index.php/unip/issue/current> Acesso em 20 de out. 2015.

SEEMANN, J. Linhas imaginárias na cartografia: a invenção do primeiro meridiano. Geograficidade. V.3, Número Especial, p. 31-44, 2013.

SILVA, L. G. Jogos e situações-problema na construção das noções de lateralidade, referências e localização espacial. In CASTELLAR, S. Educação Geográfica: teorias e práticas docentes. 3. Ed., São Paulo: Contexto, 2014.

SOBREIRA, P. H. A. Aplicação de modelos tridimensionais para o ensino de fusos horários. Revista Latino-Americana de Educação em Astronomia - RELEA, n. 13, p. 7-30, 2012.

VERRI, J. B.; ENDLICH, Â. M. A utilização de jogos aplicados no ensino de geografia. Revista Percurso, NEMO, Maringá, v. 1, n. 1, p. 65-83, 2009. 